\title{
ENVIRONMENTAL EFFICIENCY ASSESSMENT AND DIFFERENCE ANALYSIS OF INDUSTRIAL CLUSTER DISTRICTS IN CHINA
}

\author{
LI, X. $.^{1,2,3}-$ CAI, Q. ${ }^{2}-$ YANG, X. Y. ${ }^{2 *}$ \\ ${ }^{1}$ Post-Doctoral Mobile Station of Theoretical Economics, Yunnan University, Kunming 650091, \\ China \\ ${ }^{2}$ Guizhou University of Finances and Economics, Huaxi University Town, Guiyang 550025, \\ China \\ ${ }^{3}$ Research Center for Technological Innovation, Tsinghua University, Beijing 100084, China \\ *Corresponding author \\ e-mail: 116993312@qq.com; phone: +86-187-9882-7991; fax: +86-0851-8851-0477 \\ (Received $18^{\text {th }}$ Mar 2019; accepted $17^{\text {th }}$ May 2019)
}

\begin{abstract}
We used the Slacks-based Model (SBM) to calculate the environmental efficiency value of industrial cluster districts in China based on the panel data of 30 regions from 2007 to 2014, at the same time, in order to make a comparative analysis with the economic efficiency values not considering carbon emissions, the model presented by Banker, Charnes and Cooper (BCC) for estimating technical and scale inefficiencies in data envelopment analysis was used to calculate the environmental efficiency not considering the desirable output of carbon emissions, and we also analyzed the regional differences in China's environmental efficiency. The results showed that the environmental efficiency value of industrial cluster districts in China ranged between 0.83 and 0.94 not considering carbon emission, and it had a certain degree of reduction when considering the effect of undesirable output, maintaining values between 0.74 and 0.84 , and which showed that there was much room for improving the environmental condition of the industrial cluster districts in China. Carbon emission had a great impact on the environment of China's industrial cluster, which resulted in a greater degree of efficiency loss. And it showed that the carbon emissions showed a great difference to the sensitivity degree of influence on regional environmental efficiency.
\end{abstract}

Keywords: desirable output, undesirable output, carbon emissions, SBM model, economic efficiency

\section{Introduction}

In recent years, several industrial clusters were built in China. Industrial cluster has made great contribution to the development of regional economy as a unique form of industrial organization. However, because of the large-scale converging of industry in the area, it has a greater impact on the regional resources, energy and ecological system, and this way of economic development with high resource consumption and high pollution emissions will directly lead to the high carbon emission. Under the background of low carbon economy and green development, the high carbon emissions seriously restrict the sustainable development of regional ecosystem, so it requires us to carry out theoretical and practical research on the environmental impact owning to the converging of industry. As a comprehensive index to evaluate the development of economy and environment, environmental efficiency is helpful to the decision makers to find out the problems in the process of the development of regional economic, and then put forward the effective measures through assessing the environment efficiency (Cheng et al., 2014). Therefore, it has important practical significance how to promote the low-carbon 
development of China's industrial cluster districts and improve its environmental efficiency under the background of low-carbon and green development.

In recent years, the domestic and foreign scholars have also made positive progress in the research of environmental efficiency, the research mainly focuses on four aspects: the concept of environmental efficiency, the measuring method of environmental efficiency, the regional difference of environmental benefits, and the influencing factors of environmental benefits. The domestic and foreign scholars have different views on the definition of environmental efficiency. Although there is no uniform definition of environmental efficiency, the formulation also has the difference between environmental efficiency and ecological efficiency, and the definition of the environmental efficiency by WBCSD is widely recognized and accepted. At present, the domestic and foreign scholars mainly use the methods of life cycle method, multi-criteria decision making method, stochastic frontier analysis, distance function method and data envelopment analysis (DEA). For example, Maxime et al. (2006) constructed an evaluation model of environmental efficiency by using the method of JWDEA and the directed distance function. Liu et al. (2011) applied the method of super efficiency DEA to assess the ecological efficiency and the regional ecological efficiency in China. Deng Bo used the model of two stages DEA to make an empirical research on the regional ecological efficiency of China. Wang and Wu (2011) used the data development analysis model to analyze and evaluate the environmental efficiency of China's provinces and cities, and analyzed the influence factors of industrial ecological efficiency by using the Tobit regression model. Wang et al. (2011) built an environmental efficiency measurement model of different process efficiency from the perspective of system integration. About the research of regional differences of environmental benefits, the domestic and foreign scholars have studied the industrial economic development of various districts in China from many aspects and angles. For example, Li (2012) used the SBM model to analyze the environmental efficiency of the Eastern region, central region and Western region in China. Wang et al. (2011) established the energy environment measurement model by using data envelopment analysis and directed distance function and used this model to study the environmental efficiency of China's provinces. Yang and Song (2011) studied the impact of environmental efficiency from three factors of system, regional and economic operating. Qi (2012) used the DEA Max model to study the environmental efficiency of the industry in Guangxi province. The influencing factors of environmental efficiency mainly focused on the international trade and foreign direct investment (FDI) in the early research. However, the speed of economic and social development is so fast that the factors which affect the environmental efficiency are also increasing. Charmondusit and Keartpakpraek evaluated the ecological efficiency from three indicators of material consumption, water use and hazardous waste. Yang et al. (2012) believed that the GDP, FDI, structural factors and the public's environmental awareness have different levels of impact on the environmental efficiency. Tan et al. (2013) used stochastic frontier analysis and beyond logarithmic production function model to assess the environmental efficiency of three provinces in Northeast China from 1991 to 2010. Fu et al. (2013) constructed the evaluation model of coal enterprise ecological efficiency by using the DEA method. Zhang (2013) evaluated and analysed the eco-efficiency based on panel data of Western China's Provinces 2000-2010. Gao (2014) used the Tobit model to analyze the influence factors and the degree of environmental efficiency of Guangdong province and the four major regions from 2000 to 2012. Rong (2015) evaluated the environment of Western in China and analyzed the influence factors of 
environmental efficiency under the carbon emission constraints. Li et al. (2017) analyzed the evolution of environmental regulation strategy among local governments and its impact on regional ecological efficiency in china.

In summary, the researches of environmental efficiency by domestic and foreign scholars have a theoretical summary and exploration of methods, especially the research field of its concept and evaluation, and they offered a certain foundation for our further research. However, from the research point of view, the research on the industrial level and regional level is few, and the research on the regional environmental efficiency of China's industrial cluster is still in a blank stage, at the same time, the research literature about the measurement of environmental efficiency under the constraint of carbon emission is relatively few. From the aspects of the research method, most of the literatures used the data envelopment analysis model, which leads to the distortion of efficiency evaluation. Therefore, we attempted to compensate the lack of the study above, and we used the panel data from 2010 to 2015 and estimated the environmental efficiency under the constraints of carbon emission by using the SBM model to find out the differences of the regional environmental benefits of industrial clusters.

\section{Materials and methods}

\section{Research method and establishment of model}

It can be seen from the above research, most scholars in previous studies took the environmental pollution as an input or a negative output, and used the DEA model to calculate the efficiency value which including environmental pollution, but it did not take into account the relaxation problem of input-output fully, and it distorted the efficiency of the evaluation object. So Cooper et al. (2007) put forward the SBM model of data envelopment analysis with non radial and non angle (Slacks-based Model), the model considered the slack problem of the input output caused by angle and radial selection as far as possible, it could not only overcome the shortcomings of the traditional model, but also it could effectively deal with the problem of excessive input and output, it reflected the essence of efficiency evaluation more compared with other models. At present, the domestic scholars have already begun to use the SBM model to calculate the environmental benefits in China, for example, Pan and Ying (2013) used the SBM model with non radial, non angle to calculate the agricultural ecological efficiency of China's 30 provinces, and gave the way to improve the efficiency of agricultural ecology. Tian et al. (2014) calculated the China's agricultural environmental efficiency for the 2002-2012 based on the SBM model. Rong (2015) used the SBM model to calculate and analyze the static environmental efficiency of the western region under the constraints of carbon emission in the western region in China from 2000 to 2012. Gao (2014) calculated the economic efficiency values of non-expected output factors without considering the constraints of carbon emission and environmental efficiency values of non-expected output factors with considering the constraints of carbon emission of four major regions in Guangdong province by using the BCC model and SBM-V model. Huang and Shi (2015) built a SBM model including R\&D investment and calculated the environmental efficiency and the growth rate of the total factor of environment in China, and the influence factors of total factor productivity of regional environmental factors were analyzed by Tobit model based on the theory of R\&D. Guo et al. (2015) used the non expected SBM model system evaluated the total factor energy efficiency of 28 provinces in China, and the spatial convergence of the 
provincial total factor energy efficiency was studied by using the spatial econometric model based on the economic geography distance weight. Therefore, the theoretical and empirical researches showed that it was feasible to use the SBM model to evaluate the regional environmental efficiency based on the non-expected output. Based on this, according to the actual situation of industrial cluster district in China, we also use the SBM model with non-expected value to calculate the environmental efficiency of China's industrial clusters region under the constraints of carbon emission.

Due to the SBM model is introduced by the literature above, so we introduce the model of this paper according to the research of Gao (2014) and Rong (2015). The SBM model assumes that there are $n$ decision making units, each of which has input (which is expressed by $\mathrm{m}$ ), expected output (which is expressed by $\mathrm{s}_{1}$ ) and non-expected output (which is expressed by $\mathrm{s}_{2}$ ), and the three vectors are expressed as $x \in R^{m}, y^{g} \in R^{s_{1}}$ and $y^{b} \in R^{s_{2}}$, so we can define the following matrix:

$$
\begin{aligned}
X & =\left[x_{1}, x_{2}, \ldots, x_{n}\right] \in R^{m \times n} \\
Y^{g} & =\left[y_{1}^{g}, y_{2}^{g}, \ldots, y_{n}^{g}\right] \in R^{s_{1} \times n} \\
Y^{b} & =\left[y_{1}^{b}, y_{2}^{b}, \ldots, y_{n}^{b}\right] \in R^{s_{2} \times n} \\
X & >0, Y^{g}>0, Y^{b}>0
\end{aligned}
$$

The production possibility set $p$ of constant returns to scale can be defined as follows:

$$
P=\left\{\left(x, y^{g}, y^{b} \mid x \geq \lambda X, y^{g} \leq \lambda Y^{g}, y^{b} \geq \lambda Y^{b}, \lambda \geq 0\right)\right\}, \lambda \in R^{n}
$$

The above set satisfies the following three assumptions:

(1) Undesirable output of environmental efficiency has the feature of weakly disposal: if $(y, b) \in P(x), 0 \leq \theta \leq 1$, so $(\theta y, \theta b) \in P(x)$ is satisfied, and this condition means that if you want to reduce the desirable output, it is necessary to reduce the desirable output.

(2) Desirable output has the feature of disposing freedom: if $(y, b) \in P(x)$ and $y^{*} \leq y$, so $\left(y^{*}, b\right) \in P(x)$ is satisfied. This condition means that expected output can be freely controlled, but the desirable output remains the same. In generally, it is not possible for the operational efficiency of the enterprise to achieve a reduction in desirable output without a corresponding reduction in output if sustained input.

(3) Desirable output and undesirable output have zero Union: if $(y, b) \in P(x)$ and $b=0$, so $y=0$ is satisfied. This condition means that there is undesirable output without the desirable output.

According to the above, the SBM model based on the undesirable output can be expressed as follows:

$$
\rho^{*}=\min \frac{1-\frac{1}{m} \sum_{i=1}^{m} \frac{s_{i}^{-}}{x_{i 0}}}{1+\frac{1}{s_{1}+s_{2}}\left(\sum_{r=1}^{s_{1}} \frac{s_{r}^{g}}{y_{r 0}^{g}}+\sum_{r=1}^{s_{2}} \frac{s_{r}^{b}}{y_{r 0}^{b}}\right)}
$$




$$
\text { s.t. }\left\{\begin{array}{c}
x_{0}=\lambda X+s^{-} \\
y_{0}^{g}=\lambda Y^{g}-s^{g} \\
y_{0}^{b}=\lambda Y^{b}+s^{b} \\
s^{-} \geq 0, s^{g} \geq 0, s^{b} \geq 0, \lambda \geq 0
\end{array}\right.
$$

In the above formula, $s$ is the slack variable of input and output, $s^{-}$and $s^{b}$ represent the redundant of the input and the output, $s^{g}$ expresses the deficiency of expected output, $\lambda$ is the weight vector. The objective function $\rho^{*}$ strictly monotone decreasing function of $s^{-}$and $s^{b}$, and $\rho^{*} \in(0,1)$. According to the research of Cooper et al. (2007), the loss of environmental efficiency can be decomposed into:

(1) Input redundancy

$$
I E_{x}=\frac{1}{m} \sum_{i=1}^{m} \frac{s_{i}^{-}}{x_{i 0}}
$$

It means reduced proportion of input elements.

(2) Desirable output deficiency

$$
I E_{y}=\frac{1}{s_{1}+s_{2}} \sum_{r=1}^{s_{1}} \frac{s_{r}^{g}}{y_{r 0}^{g}}
$$

It means the expansion ratio of expected output.

(3) Undesirable output redundancy

$$
I E_{u}=\frac{1}{s_{1}+s_{2}} \sum_{r=1}^{s_{2}} \frac{s_{r}^{b}}{y_{r 0}^{b}}
$$

\section{Selection of the research indexes and data sources}

Owning to the environmental efficiency reflects the development of coordination status of resource conservation, environmental protection and regional economic growth. Therefore, we mainly consider the three factors during selecting the rating index of the environmental efficiency. The domestic and foreign scholars have conducted a lot of research about evaluation index of environmental efficiency at the current, based on the existing research on the input indicators and output indicators, and combining with the actual research object, the index selection and calculation methods in this paper are as follows:

(1) Input index

Energy input: It shows that how much energy is used in the process of development in the industrial clusters region. Because the total energy consumption statistics is not appeared yet in all provinces in China over the years, therefore, according to the research result of Guo et al. (2015) as well as the physical consumption of the main energy sources in each province and the conversion coefficient, the calculation method is as follows: 


$$
E_{i, t}=\sum_{j=1}^{n} e_{i, t, j} \bullet c_{j}
$$

Among them, $E_{\mathrm{i}, \mathrm{t}}$ represents the total energy consumption of the industrial cluster region $\mathrm{i}$ in $\mathrm{t}$ year, $e_{\mathrm{i}, \mathrm{t} j \mathrm{j}}$ represents the energy $j$ consumption of the industrial cluster region $i$ in $t$ year, $c_{j}$ represents the conversion coefficient of energy $i$.

Capital input: In recent years, a large number of literatures have tried to estimate the stock of capital in China, and the different methods used by different scholars. Some scholars used the method of perpetual inventory, while some scholars used the annual average balance of net fixed assets as capital stock. Here, according to the research result of Rong (2015) and Zhang et al. (2004), we use the method of perpetual inventory to estimate capital stock. The basic formula is as follows:

$$
K_{t}=I_{t}+(1-\delta) K_{t-1}
$$

Among them, $K_{\mathrm{t}}$ represents the capital stock at time $\mathrm{t}$, and $K_{\mathrm{t}-1}$ represents the capital stock at time $t-1$. $I_{t}$ represents the amount of investment at time $t, \delta$ represents the depreciation rate. We take 2007 year for the initial years of the calculation, and take the total amount of fixed capital formation divided by $10 \%$ as the initial capital stock of provinces and municipalities in 2005 year, the formation total of annual fixed capital as the amount of investment, and we calculate the capital stock with of the depreciation rate (which is $9.6 \%$ ).

Labor factor input: We take the annual average number of employees in the enterprises in the industrial cluster region as the labor input.

Land input: At present, different scholars have different represent ways, some scholars used the built area, some scholars used the area of crop planting and aquaculture, and some scholars used the area of cultivated land and construction land. Here, we use the built area as the evaluation index.

(2) Desirable output

We use the GDP of every industrial clusters region to show the expected output. And the GDP deflator is converted to the constant price GDP in 2007 as the base year.

(3) Undesirable output

In this paper, owning to we study the environmental efficiency under the constraint of carbon emission. Therefore, we choose the index of $\mathrm{CO}_{2}$ emission as the non-expected output. Because the statistics of carbon emissions of monitoring the various provinces and cities in China is not exist, therefore, according to the studies of Rong (2015), and the estimation method of IPCC national greenhouse gas emission inventory guide in the 2006, we take the sum of eight main sources of the product of energy consumption and the respective carbon dioxide emission factors to calculate the $\mathrm{CO}_{2}$ emission. Specific calculation formula is as follows:

$$
m_{c o_{2}}=\sum_{i=1}^{8} m_{i} \times Q D W_{i} \times E_{i}
$$

Among them, $m_{\mathrm{CO}_{2}}$ represents the emission of $\mathrm{CO}_{2}(10000 \mathrm{t}), m_{\mathrm{i}}$ represents the energy consumption by end $\left(10000 \mathrm{t}, 100\right.$ million $\left.\mathrm{m}^{3}\right), Q D W_{\mathrm{i}}$ represents low calorific value of 
various types of energy $\left(\mathrm{KJ} / \mathrm{Kg}, \mathrm{KJ} / \mathrm{m}^{3}\right), E_{\mathrm{i}}$ represents $\mathrm{co}_{2}$ emission factors of various types of $\mathrm{CO}_{2}(\mathrm{Kg} / \mathrm{TJ})$.

(4) Control variables

The regional energy efficiency is not only affected by the factors such as capital, labor and energy inputs, but also is related to the technological progress, regional industrial structure and other variables. According to the research of Guo et al. (2015), we select three control variables in this paper:

Investment of $R \& D$ : It is expressed by the value of the ratio of $R \& D$ investment to regional GDP in industrial cluster region. It represents the scientific and technological innovation of the regional enterprises and the technical progress of the industry, and the improvement of the production efficiency, and thus improving the overall environmental efficiency of the region.

Industrial structure: It is expressed by the value of the ratio of the second industry in the industrial clusters region to the GDP. Industry is the largest energy consumption in the three major industries, and the efficiency of the industry is relatively low, the greater the proportion may lead to the low efficiency of overall.

System variable: It is expressed by the value of the ratio of fiscal expenditure to GDP in industrial clusters region. The index reflects the government's interference extent to the regional economy, and it affects the regional environmental efficiency to a certain extent.

\section{Data source description}

The input-output data are derived from the years of "China Statistical Yearbook", "China Environmental Yearbook", "China Environmental Statistics Yearbook", "Chinese Energy Statistics Yearbook", "China Statistical Yearbook of science and technology", "China land and resources Yearbook", "IPCC national greenhouse gas emission inventory in 2006", and provincial Environmental Statistics Bulletin, and the composition of 2007-2014 in 30 provinces, autonomous regions and municipalities. Taking into account the consistency and availability of data, the panel data set of Tibet and Taiwan, Hongkong, and Macao are not included in the study. In addition, we still divide China into four regions of eastern, central, western and and northeast according to the traditional division method, which includes 11 provinces in the eastern region, 8 provinces in central region and including 11 provinces in western (Except Tibet) when we analyze the environmental efficiency of industrial cluster region.

\section{Results and discussion}

\section{Overall environmental efficiency evaluation}

We use the SBM model to calculate the value of China's industrial clusters region from 2007 to 2014, and in order to compare the efficiency environment with the situation which does not consider the carbon emissions, we use the BCC model to calculate the efficiency environment which not consider the carbon emissions. We use Matlab7.0 to calculate the economic efficiency and environmental efficiency. The value of environmental efficiency and economic efficiency of China's industrial cluster region from 2007 to 2014 in two cases are shown in Table 1 and Figure 1. As we can see from Table 1 and Figure 1, the environmental efficiency value of industrial cluster districts in China ranged between 0.83 and 0.94 not considering the carbon emissions and other 
undesirable output if we use the BCC model to evaluate the efficiency of economic growth of industrial cluster districts in China. But the efficiency of China's industrial cluster districts has a certain degree of reduction compared with before when we consider the effect of undesirable output, and the value ranged between 0.74 and 0.84 , and they are not up to 1 , it shows that there is much room to improve the environmental condition of the industrial cluster districts in China.

Table 1. The value of environmental efficiency and economic efficiency from 2007 to 2014

\begin{tabular}{c|c|c|c}
\hline Year & Environmental efficiency value & Year & Economic efficiency value \\
\hline 2007 & 0.81 & 2007 & 0.94 \\
2008 & 0.79 & 2008 & 0.90 \\
2009 & 0.76 & 2007 & 0.86 \\
2010 & 0.78 & 2010 & 0.87 \\
2011 & 0.80 & 2011 & 0.91 \\
2012 & 0.74 & 2012 & 0.83 \\
2013 & 0.77 & 2013 & 0.85 \\
2014 & 0.84 & 2014 & 0.9 \\
\hline
\end{tabular}

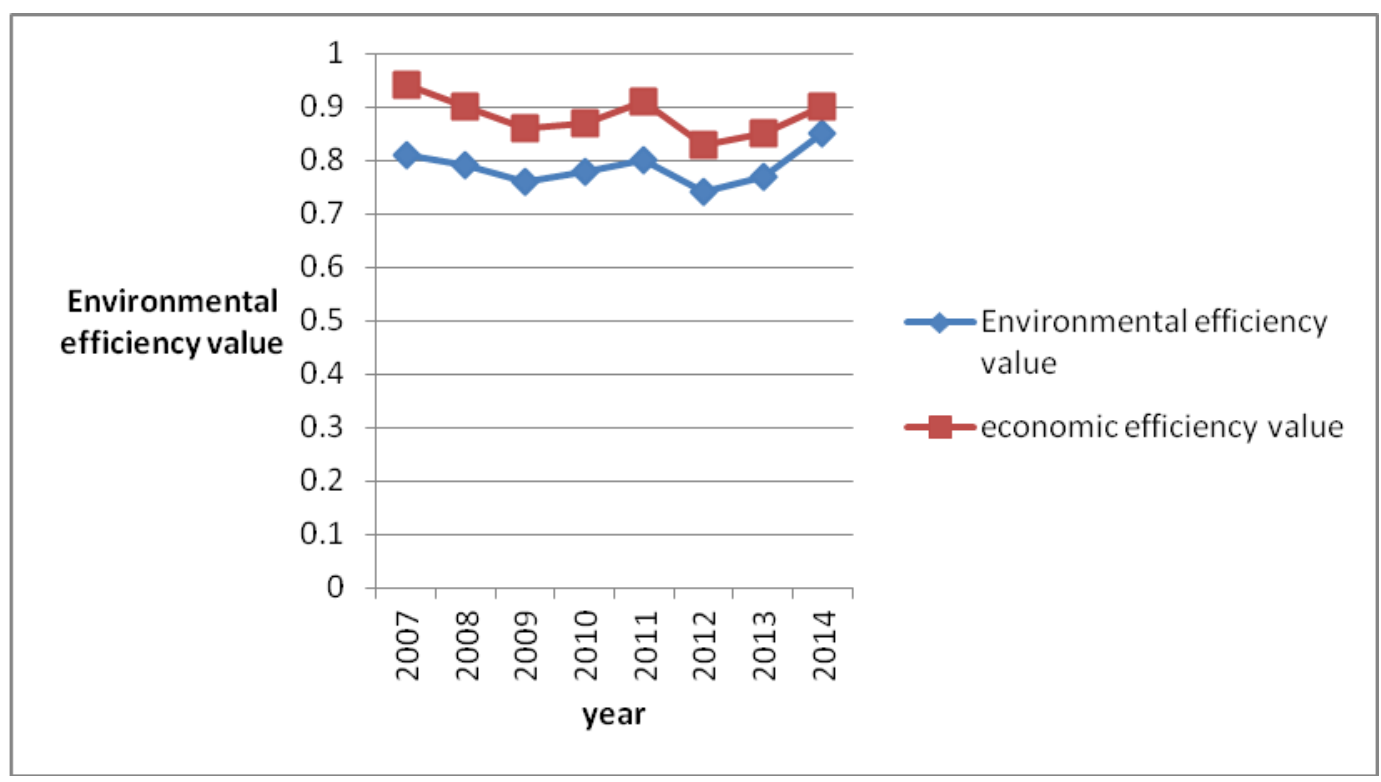

Figure 1. Environmental efficiency value of carbon emission and not considering carbon emission from 2007 to 2014 years

The result shows that the carbon emission has a great impact on the environment of China's industrial cluster, and it results in a greater degree of efficiency loss, so the carbon emission has become a problem that cannot be ignored in the environmental governance. It means that the efficiency evaluation is distorted in the case of nonexpected output without taking into account the pollution discharge, and it also proves that using the SBM model to evaluate the efficiency of carbon emission is suitable, and this model improves the accuracy and credibility of the environmental efficiency evaluation in the presence. At the same time, from the perspective of the time 
dimension, the environmental efficiency value of China's industrial cluster region displays the style of "W" under the constraint of carbon emission in the sample range, and the change is relatively large. But they continue to narrow the gap, the main reason is that the government in China implemented the energy-saving emission reduction measures, and put forward the concept of ecological civilization construction, people's awareness of environmental protection had been enhanced.

\section{Analysis on the difference of regional environmental efficiency}

According to the general method of regional division, we take the four regions of the Eastern, Central, Western and Northeastern as the research unit in this paper. Also, we use the BCC model to calculate the economic efficiency value for the China's industrial clusters in Eastern region, Central region, Western region and Northeast region from 2007 to 2014 not considering the carbon emissions, and then we use the SBM model to calculate the economic efficiency value for the China's industrial cluster districts in Eastern, Central, Western and Northeast from 2007 to 2014 with considering the carbon emissions, and explore the difference and change features. Owning to the limited space and combine with the characteristics of the stage of China's regional economic development, we only show the results in 2008, 2010, 2012 and 2014 in Tables 2 and 3.

(1) Environmental efficiency of various regions of China's industrial cluster not considering carbon emissions. As we can see from Table 2 and Figure 2, the average value of environmental efficiency of the Eastern region, the Central region, the Northeast region and the Western region from 2007 to 2014 is $0.806,0.686,0.959$ and 0.571 from the perspective of regional, and the result is consistent with the conclusions of the existing literatures, and it means that the eastern region has achieved some results after transforming to the intensive economic growth mode with low consumption, low pollution and high efficiency. At the same time, it reflects a good phenomenon that the environment quality of traditional industry in underdeveloped areas will not be better than the development area, the economy of the eastern region in China is not only better than the central region, the northeast region and the western region, but also the environmental pollution control and to keep less pollution obviously are still better than less developed areas. In addition, the difference of environmental efficiency between the central region and the eastern region decreases with time, and the difference of environmental efficiency among the western region, the northeast region and the central region tends to increase, this result means that the west is in a very unfavorable situation in terms of environmental efficiency. In addition, the annual average value of the environmental efficiency of the eastern region changes relatively stable, while the annual average value of the central region, the northeast region and the western region change greatly from the change trend from 2007 to 2014.

From the level of provincial, the environmental efficiency of the developed areas in the eastern region such as Tianjin, Beijing, Jiangsu, Shanghai, Guangdong, Zhejiang, Shandong has been in the forefront in the above 8 years. The reason is that the modern industrial system which takes the modern service industry as the leading industry in the developed area of eastern region has been built to mature, and the energy consumption continues to decline, and the formulation and implementation of energy-saving emission reduction measures is also ahead of other regions. So it can be seen that changing the mode of economic development and promoting the optimization and upgrading of the industrial structure is very important to improve the efficiency of the regional environment. The lowest efficiency value is Shanxi Province where the coal industry as 
the core of the in the central region, and because the province ignored the development of technology in the process of industrial, so it results in inefficient use of resources and negative influence on environment efficiency. The environmental efficiency of underdeveloped areas in the western region such as Ningxia, Qinghai, Guizhou have been in the lag in the above 8 years, and it shows that the economic growth mode of the western region is still mainly extensive, and the economic development is relatively backward.

In summary, the environmental efficiency of China's industrial cluster regional is decreasing from coastal areas to inland and from east to west, and the differences of regional environmental efficiency presents the features of marginalization.

Table 2. The environmental efficiency (not considered the carbon emissions)

\begin{tabular}{|c|c|c|c|c|c|}
\hline Province & 2008 & 2010 & 2012 & 2014 & Mean value \\
\hline Beijing & 1 & 1 & 1 & 1 & 1 \\
\hline Tianjin & 1 & 1 & 1 & 1 & 1 \\
\hline Hebei & 0.90 & 0.84 & 1 & 0.94 & 0.92 \\
\hline Hainan & 0.96 & 0.93 & 0.91 & 0.97 & 0.935 \\
\hline Shanghai & 1 & 1 & 1 & 1 & 1 \\
\hline Jiangsu & 0.95 & 0.92 & 0.90 & 0.97 & 0.925 \\
\hline Zhejiang & 0.96 & 0.91 & 0.90 & 0.98 & 0.928 \\
\hline Fujian & 0.94 & 0.93 & 0.90 & 0.96 & 0.923 \\
\hline Shandong & 0.93 & 0.91 & 0.88 & 0.95 & 0.91 \\
\hline Guangdong & 1 & 1 & 1 & 1 & 1 \\
\hline Eastern average & 0.964 & 0.944 & 0.949 & 0.979 & 0.959 \\
\hline Liaoning & 0.75 & 0.70 & 0.65 & 0.80 & 0.675 \\
\hline Jilin & 0.69 & 0.64 & 0.60 & 0.78 & 0.628 \\
\hline Heilongjiang & 0.65 & 0.61 & 0.56 & 0.74 & 0.59 \\
\hline Northeast average & 0.717 & 0.65 & 0.603 & 0.773 & 0.686 \\
\hline Shanxi & 0.46 & 0.48 & 0.43 & 0.5 & 0.468 \\
\hline Anhui & 0.9 & 0.92 & 0.94 & 0.95 & 0.926 \\
\hline Jiangxi & 0.92 & 0.88 & 0.96 & 0.97 & 0.933 \\
\hline Henan & 0.72 & 0.68 & 0.76 & 0.8 & 0.74 \\
\hline Hubei & 0.86 & 0.88 & 0.90 & 0.91 & 0.886 \\
\hline Hunan & 0.88 & 0.9 & 0.92 & 0.94 & 0.91 \\
\hline Central average & 0.79 & 0.79 & 0.818 & 0.845 & 0.806 \\
\hline Inner Mongolia & 0.56 & 0.58 & 0.53 & 0.6 & 0.568 \\
\hline Guangxi & 0.65 & 0.7 & 0.74 & 0.8 & 0.723 \\
\hline Chongqing & 0.99 & 0.96 & 0.98 & 0.95 & 0.97 \\
\hline Sichuan & 0.71 & 0.75 & 0.79 & 0.84 & 0.773 \\
\hline Guizhou & 0.32 & 0.36 & 0.31 & 0.37 & 0.34 \\
\hline Yunnan & 0.58 & 0.60 & 0.64 & 0.68 & 0.625 \\
\hline Shanxi & 0.57 & 0.59 & 0.62 & 0.65 & 0.608 \\
\hline Gansu & 0.52 & 0.5 & 0.54 & 0.57 & 0.53 \\
\hline Qinghai & 0.44 & 0.43 & 0.47 & 0.5 & 0.46 \\
\hline Ningxia & 0.42 & 0.41 & 0.38 & 0.36 & 0.393 \\
\hline Xinjiang & 0.43 & 0.4 & 0.41 & 0.45 & 0.423 \\
\hline Western average & 0.563 & 0.571 & 0.535 & 0.615 & 0.571 \\
\hline
\end{tabular}


Table 3. The environmental efficiency from 2007 to 2014 years (considering the carbon emissions)

\begin{tabular}{c|c|c|c|c|c}
\hline Province & $\mathbf{2 0 0 8}$ & $\mathbf{2 0 1 0}$ & $\mathbf{2 0 1 2}$ & $\mathbf{2 0 1 4}$ & Mean value \\
\hline Beijing & 1 & 1 & 0.96 & 1 & 0.978 \\
Tianjin & 1 & 0.94 & 0.95 & 1 & 0.956 \\
Hebei & 0.78 & 0.8 & 0.92 & 0.88 & 0.845 \\
Hainan & 0.92 & 0.87 & 0.84 & 0.88 & 0.878 \\
Shanghai & 1 & 0.95 & 0.94 & 1 & 0.953 \\
Jiangsu & 0.90 & 0.86 & 0.82 & 0.95 & 0.856 \\
Zhejiang & 0.90 & 0.87 & 0.84 & 0.98 & 0.873 \\
Fujian & 0.89 & 0.87 & 0.83 & 0.95 & 0.86 \\
Shandong & 0.88 & 0.83 & 0.82 & 0.94 & 0.843 \\
Guangdong & 1 & 0.94 & 0.96 & 1 & 0.956 \\
Eastern average & 0.927 & 0.893 & 0.888 & 0.958 & 0.917 \\
Liaoning & 0.68 & 0.6 & 0.55 & 0.7 & 0.583 \\
Jilin & 0.59 & 0.54 & 0.50 & 0.65 & 0.528 \\
Heilongjiang & 0.54 & 0.51 & 0.46 & 0.6 & 0.488 \\
Northeast average & 0.603 & 0.55 & 0.503 & 0.65 & 0.577 \\
Shanxi & 0.4 & 0.41 & 0.37 & 0.39 & 0.393 \\
Anhui & 0.8 & 0.82 & 0.84 & 0.85 & 0.828 \\
Jiangxi & 0.82 & 0.78 & 0.86 & 0.87 & 0.833 \\
Henan & 0.62 & 0.58 & 0.66 & 0.71 & 0.643 \\
Hubei & 0.76 & 0.79 & 0.80 & 0.82 & 0.793 \\
Hunan & 0.81 & 0.84 & 0.85 & 0.87 & 0.84 \\
Central average & 0.702 & 0.703 & 0.73 & 0.752 & 0.722 \\
Inner Mongolia & 0.46 & 0.48 & 0.43 & 0.5 & 0.468 \\
Guangxi & 0.55 & 0.6 & 0.64 & 0.7 & 0.623 \\
Chongqing & 0.88 & 0.86 & 0.89 & 0.9 & 0.883 \\
Sichuan & 0.61 & 0.65 & 0.69 & 0.74 & 0.673 \\
Guizhou & 0.22 & 0.26 & 0.21 & 0.27 & 0.24 \\
Yunnan & 0.48 & 0.50 & 0.54 & 0.58 & 0.525 \\
Shanxi & 0.47 & 0.49 & 0.52 & 0.55 & 0.508 \\
Gansu & 0.42 & 0.4 & 0.44 & 0.47 & 0.433 \\
Qinghai & 0.34 & 0.33 & 0.37 & 0.4 & 0.36 \\
Ningxia & 0.32 & 0.31 & 0.28 & 0.26 & 0.293 \\
Xinjiang & 0.33 & 0.3 & 0.31 & 0.35 & 0.323 \\
Western average & 0.462 & 0.471 & 0.484 & 0.52 & 0.484 \\
\hline & & & &
\end{tabular}

It can be seen from Figure 3 that the gap of the environmental efficiency value among the four major regions is still large. Compared Figure 2 with Figure 3, we can know that the environmental efficiency value has a certain degree of reduction compared with not considering the carbon emissions. From the perspective of regional, carbon emission has a great impact on the differences degree of regional environmental efficiency. In the consideration of carbon emissions, we found that the environmental efficiency of the eastern region declined, but the change extent is slightly, however, the environmental efficiency value of the central region, the eastern region and the western 
region decreased significantly, and it also shows that the difference of sensitivity degree of the influence of carbon emissions on the regional environmental efficiency.

(2) The environmental efficiency of various regions of China's industrial clusters with considering the carbon emissions. In the case of considering carbon emissions, the trends of environmental efficiency in the four regions are shown in Table 3 and in Figure 3.

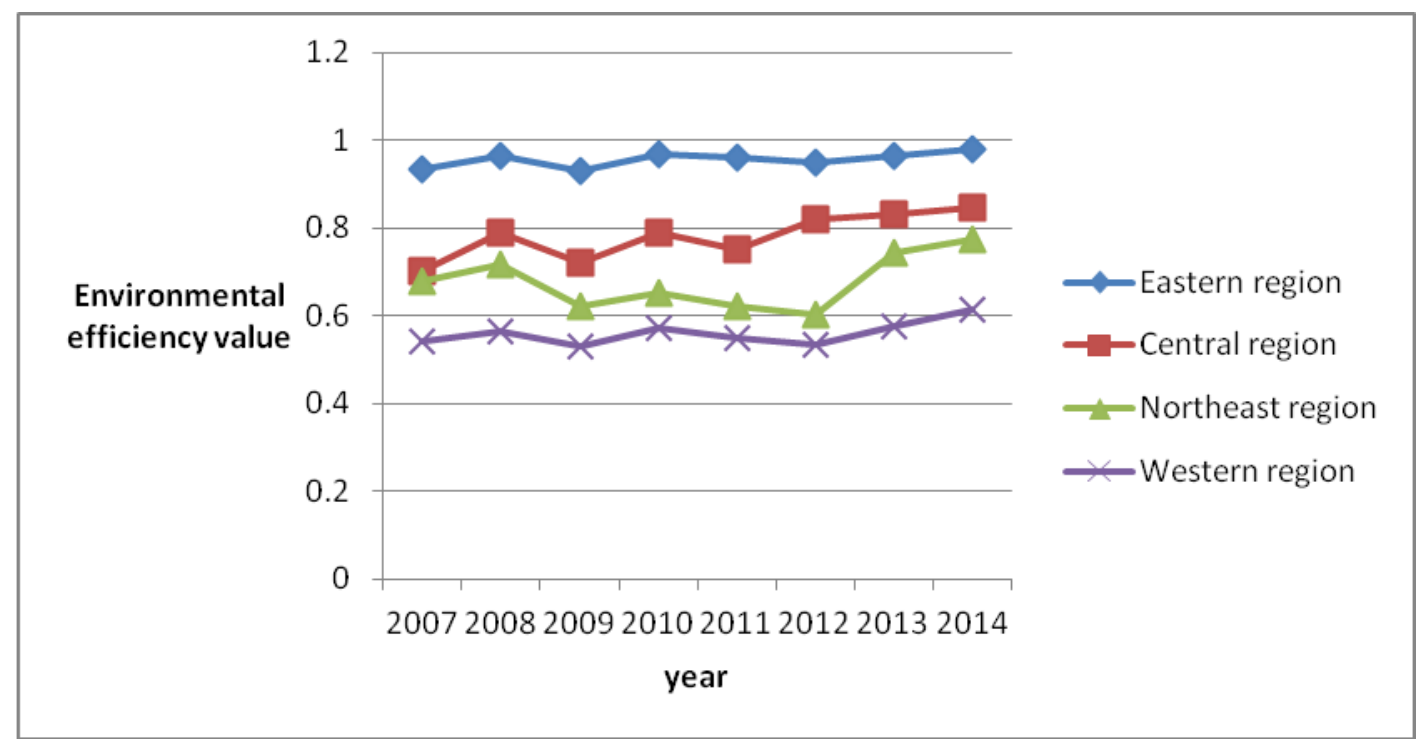

Figure 2. Change trend of regional environmental efficiency not considering the carbon emissions

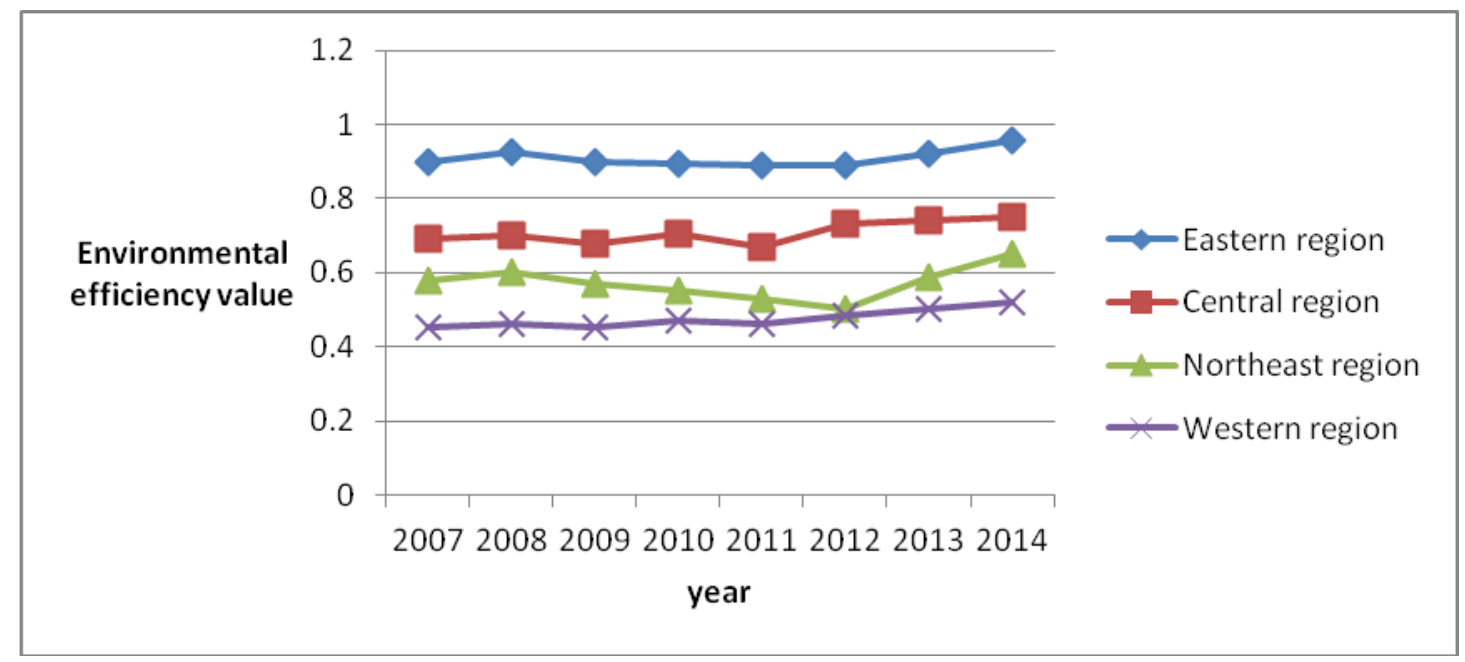

Figure 3. Change trend of regional environmental efficiency with considering carbon emissions

\section{Conclusions}

According to the above research, we get the main conclusions are as follows:

(1) The environmental efficiency value of industrial clusters region in China ranged between 0.83 and 0.94 without considering the carbon emissions and other undesirable output if we use the BCC model to evaluate the efficiency of economic growth of 
industrial cluster districts in China. But the efficiency of China's industrial clusters region has a certain degree of reduction compared with before when we consider the effect of undesirable output, and the value ranged between 0.74 and 0.84 , and they are not up to 1 , it shows that there is much room to improve the environmental condition of the industrial cluster districts in China.

(2) The environmental efficiency value of China's industrial cluster region display the style of "W" under the constraint of carbon emission in the sample range, and the change is relatively large. But the gap is becoming narrow continuously, the main reason is that the government in China implemented the energy-saving emission reduction measures, and put forward the concept of ecological civilization construction, people's awareness of environmental protection had been enhanced, but there exits occasional rebound phenomenon.

(3) The carbon emission has a great impact on the environment of China's industrial cluster, and it results in a greater degree of efficiency loss, and it also proves that the SBM model is suitable to evaluate the efficiency of carbon emission, and it improves the accuracy and credibility of the environmental efficiency evaluation.

(4) The results proved that the highest environmental efficiency is the eastern region, the worst environmental efficiency is the western region. In addition, the annual average value of the environmental efficiency of the eastern region changes relatively stable, while the annual average value of the central region, the northeast region and the western region change greatly. That is to say, the environmental efficiency of China's industrial cluster regional is decreasing from coastal areas to inland and from east to west, and the differences of regional environmental efficiency presents of marginalization.

(5) In the case of considering the carbon emissions, the gap among the eastern region, the central region, the northeast region and the western region is still relatively large, and compared with not considering the carbon emissions, the environmental efficiency value has a certain degree of reduction. From the perspective of regional, carbon emission has a great impact on the differences degree of regional environmental efficiency. In the consideration of carbon emissions, we found that the environmental efficiency of the eastern region declined, but the change extent is slightly, however, the environmental efficiency value of the central region, the eastern region and the western region decreased significantly.

Environmental efficiency evaluation is a relatively new issue. However, there are still some problems and shortcomings. Many work needs to be further studied and improved in the future.

(1) We can analyze the mechanism of location selection and product structure on environmental efficiency from the perspective of industry and enterprise.

(2) We can compare China's environmental efficiency with other countries in the world, and find out the gap between China and other countries.

(3) We can evaluate the total factor environmental efficiency under taking into account a variety of pollutants (such as $\mathrm{CO}_{2}, \mathrm{SO}_{2}, \mathrm{COD}$ ), so we can better find the environment problems.

Acknowledgements. This article is funded by the National Social Science Fund Project (14CJY002), joint fund project of Ministry of Commerce and Guizhou University of finance and economics (2017SWBZD19). 


\section{REFERENCES}

[1] Cheng, J. H., Sun, Q., Guo, M. J., Xu, W. Y. (2014): Study on regional differences and dynamic evolution of China's ecological efficiency. - China Population, Resources and Environment 24(1): 47-53.

[2] Cooper, W. W., Seiford, L. M., Tone, K. (2007): Data Envelopment Analysis. Second Ed. - Kluwer Academic Publishers, Boston.

[3] Fu, L. N., Chen, X. H., Leng, Z. H. (2013): Urban agglomerations eco-efficiency analysis based on super efficiency DEA model: case study of Chang-Zhu-Tan " $3+5$ " urban agglomeration. - China Population, Resources and Environment 23(4): 169-175.

[4] Gao, W. (2014): Study on the regional differences and influencing factors of industrial environmental efficiency in Guangdong province. - East China University of Science and Technology 4: 22-28.

[5] Guo, W., Sun, T., Zhou, P. (2015): Evaluation of regional total factor energy efficiency and its spatial convergence in China: based on an improved non-expected SBM model. Systems Engineering 33(5): 70-74.

[6] Huang, Y. C., Shi, Q. P. (2015): Research on the regional environmental efficiency and environmental factors in China: analysis of the SBM model based on including R \& D investment. - China Population, Resources and Environment 25(12): 25-29.

[7] Li, J. (2012): Study on Differences and Regulations of Environmental Efficiency in China. - Social Sciences Academic Press, Beijing.

[8] Li, X., Wang, Y., Li, C. L. (2017): Evolution of environmental regulation strategy among local governments and its impact on regional ecological efficiency in China. Environmental Engineering \& Management Journal 16(10): 2425-2433.

[9] Liu, B. Q., Li, L. M., Song, J. K. (2011): China Regional eco-efficiency measurement and difference analysis. - Techno-Economics and Management Research 10: 3-6.

[10] Maxime, D., Marcotte, M., Arcand, Y. (2006): Development of eco-efficiency indicators for the Canadian food and beverage industry. - Journal of Cleaner Production 14(6-7): 636-648.

[11] Pan, D., Ying, R. Y. (2013): Agricultural eco-efficiency evaluation in China based on SBM model. - Acta Ecologica Sinica 33(12): 3837-3845.

[12] Qi, H. Y. (2012): Study on Industrial Environmental Efficiency and Its Influencing Factors in Guangxi Province. - School of Economics and Management, Guangxi Normal University.

[13] Rong, J. B. (2015): Evaluation of environmental efficiency in China's western region under the constraint of carbon emission. - Zhejiang University 3: 18-29.

[14] Tan, X., Cao, Y. Q., Shi, L. (2013): A comparative study of environmental efficiency in three northeastern provinces: 1991-2010. - Productivity Study 4: 109-112.

[15] Tian, W., Yang, L. J., Jiang, J. (2014): Measurement and analysis of China's agricultural environmental efficiency under the perspective of low carbon: Based on the SBM model of the non-expected output. - The Observation of China's Rural 5: 59-62.

[16] Wang, E. X., Wu, C. Y. (2011): Study on the differences of spatial temporal for inter provincial ecological efficiency in China based on super efficiency DEA model. - Journal of Management Science 8(3): 443-447.

[17] Wang, K. L., Yang, B. C., Yang. L. (2011): Environmental efficiency measurement model and empirical study of interprovincial energy utilization in China. - Systems Engineering 29(1): 8-14.

[18] Yang, J., Song, M. L. (2011): Research on regional environmental efficiency of China under the vision of sustainable development: Based on the Super-SBM and panel data model. - Business Economics and Management 9: 57-62.

[19] Yao, Y. L., Jia, K. L., Wang, J. F., Feng, S. (2012): Space analysis on regional ecoefficiency based on DEA model: a case study for Ningxia Hui autonomous region. Journal of Xinyang Normal University: Natural Science Edition 25(3): 324-328. 
[20] Zhang, J., Wu, G., Zhang, J. (2004): China's provincial material capital stock estimate of 1952-2000. - Economic Research Journal 10: 35-44.

[21] Zhang, X. M. (2013): The Evaluation and dynamic analysis of eco-efficiency: based on panel data of western China's provinces 2000-2010. - Economic Theory and Business Management 2: 78-85. 